\title{
One-Pot Synthesis of Poly(glycerol-co-succinic acid) Nanogels for Dermal Delivery
}

Fatemeh Zabihi ${ }^{\mathrm{a}, \mathrm{b}}$, Hanna Koeppe ${ }^{\mathrm{a}}$, Katharina Achazi ${ }^{\mathrm{a}}{ }^{\text {Sarah Hedtrich }}{ }^{\mathrm{b}, \mathrm{c}}$ and Rainer Haag ${ }^{\mathrm{a}}$

anstitut für Chemie und Biochemie, Freie Universität Berlin, Takustr. 3, 14195, Berlin, Germany

${ }^{b}$ Institute of Pharmacy (Pharmacology and Toxicology), Freie Universität Berlin, Takustr. 3, D-14195 Berlin, Germany

${ }^{c}$ University of British Colombia, Faculty of Pharmaceutical Sciences, 2405 Wesbrook Mall, V6T1Z3 Vancouver, Canada

Corresponding author: Rainer Haag; haag@chemie.fu-berlin.de and Sarah Hedtrich; sarah.hedtrich@ubc.ca 

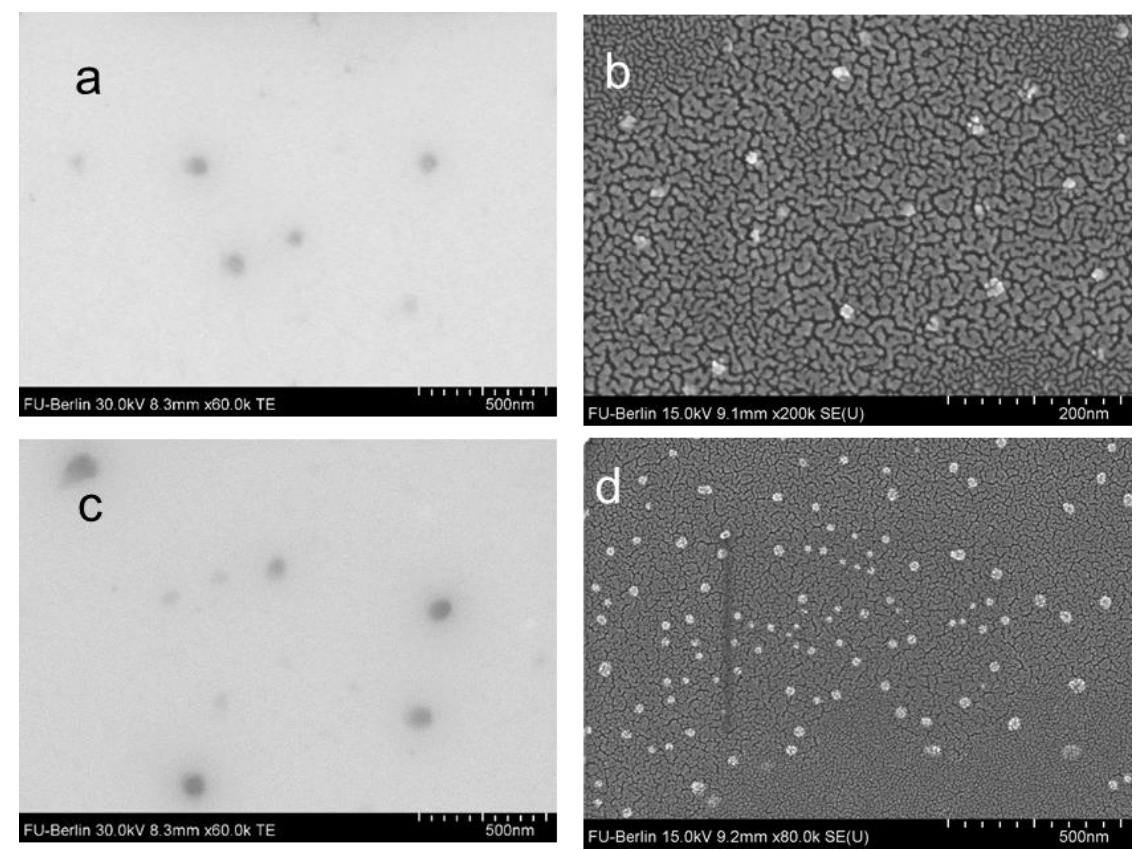

Figure S1. TEM images of (a) CPSG (c) TPSG, SEM images of (b) CPSG and (d) EPSG.
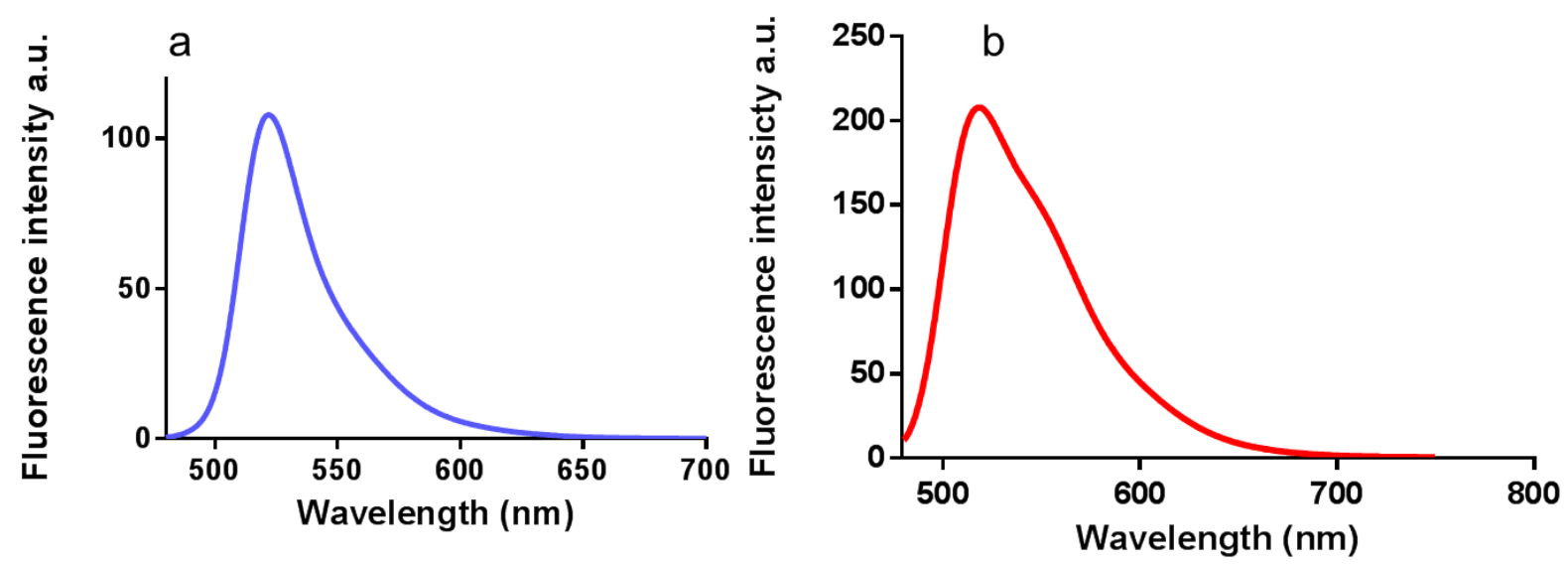

Figure S2. Fluorescence spectra of the (a) FITC labeled CPSG and (b) EPSG nanogels show at 500-600 nm. 

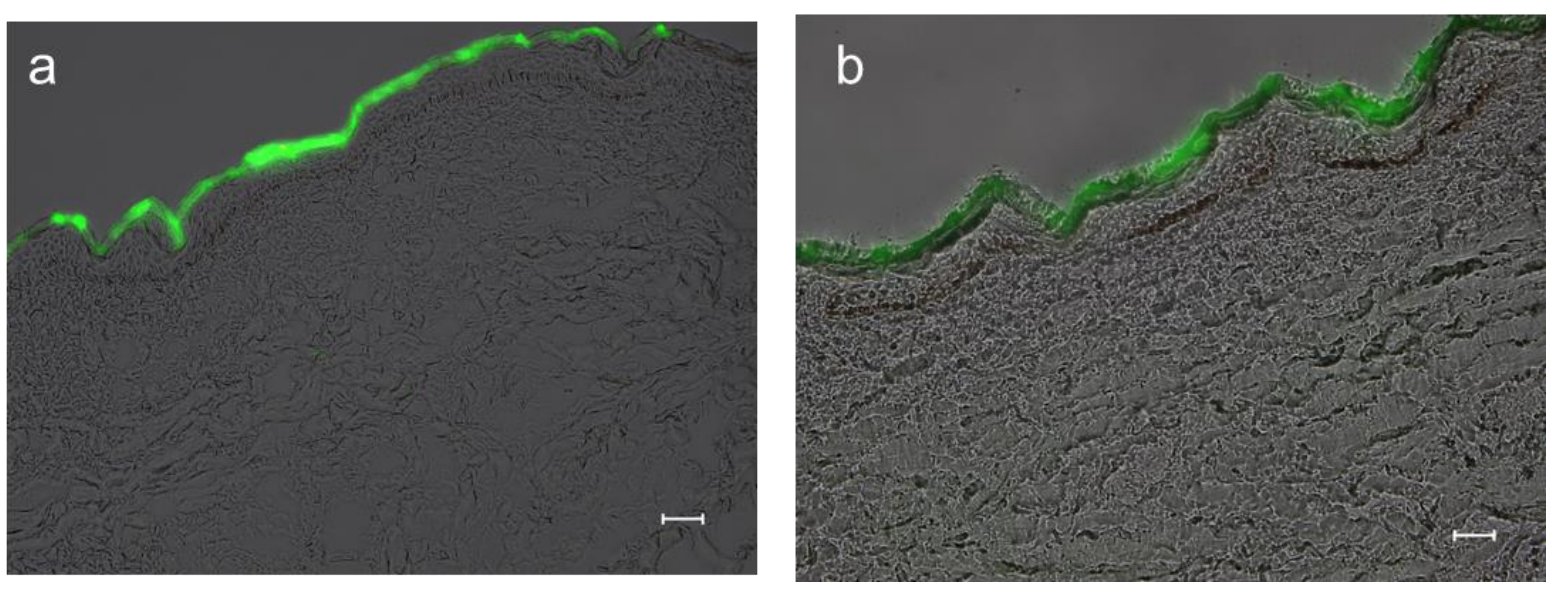

Figure S3. Representative overlay microscopy images of bright field and fluorescence human skin after $6 \mathrm{~h}$ topical application of (a) FITC labeled CPSG and (b) EPGS nanogels.

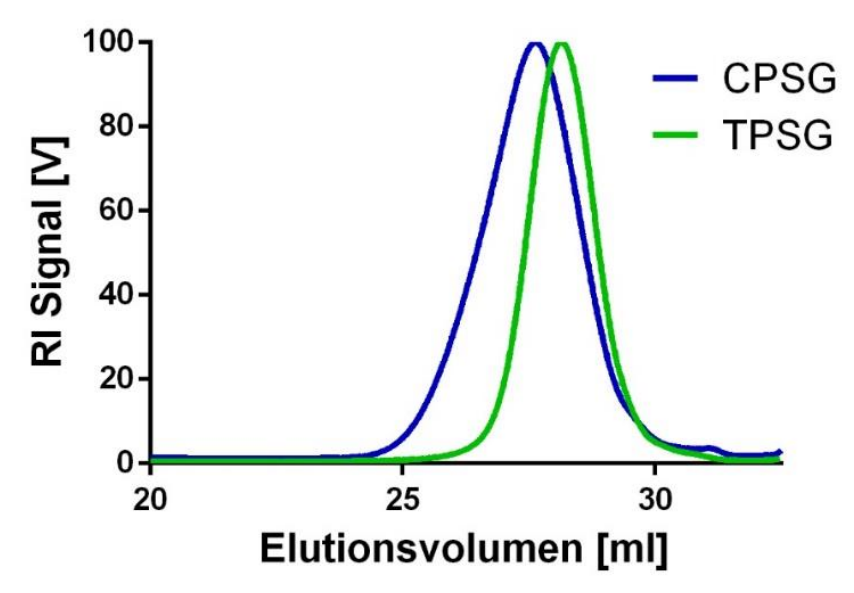

Figure S4. GPC data of CPSG and TPSG in $\mathrm{D}_{2} \mathrm{O}$. 
Signals of aromatic protons

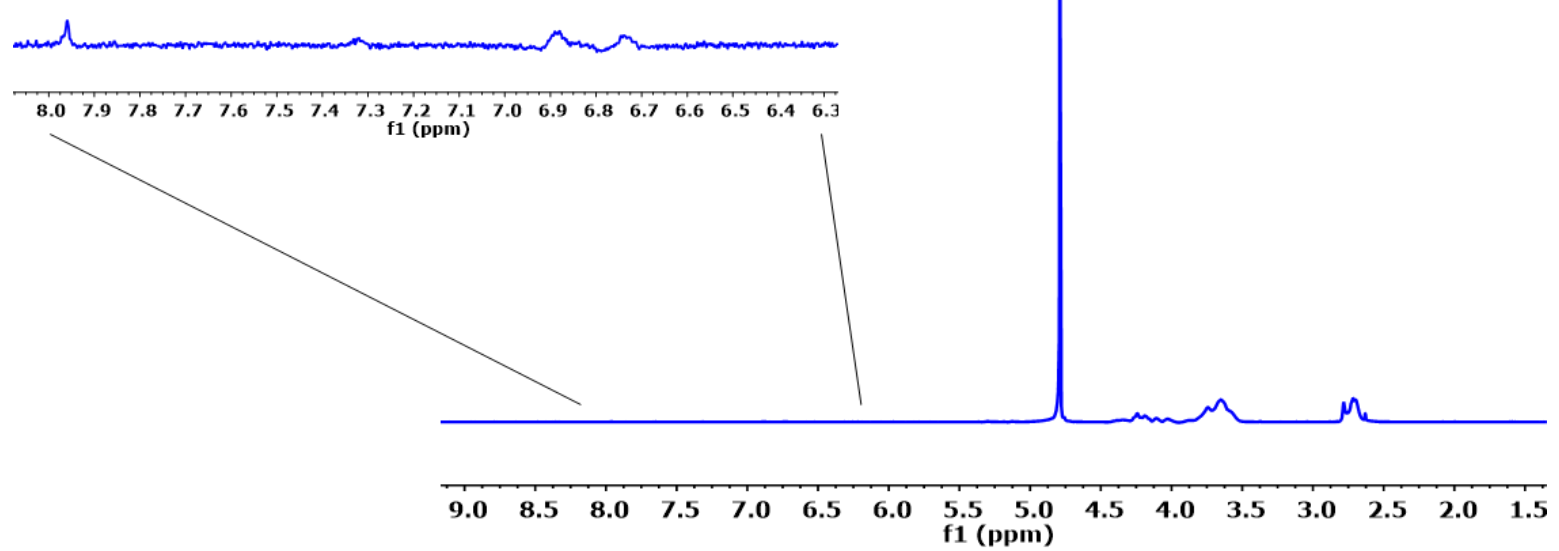

Figure S5. ${ }^{1} \mathrm{H}$ NMR spectrum FITC-labeled CPSG in $\mathrm{D}_{2} \mathrm{O}$.

Signals of aromatic protons

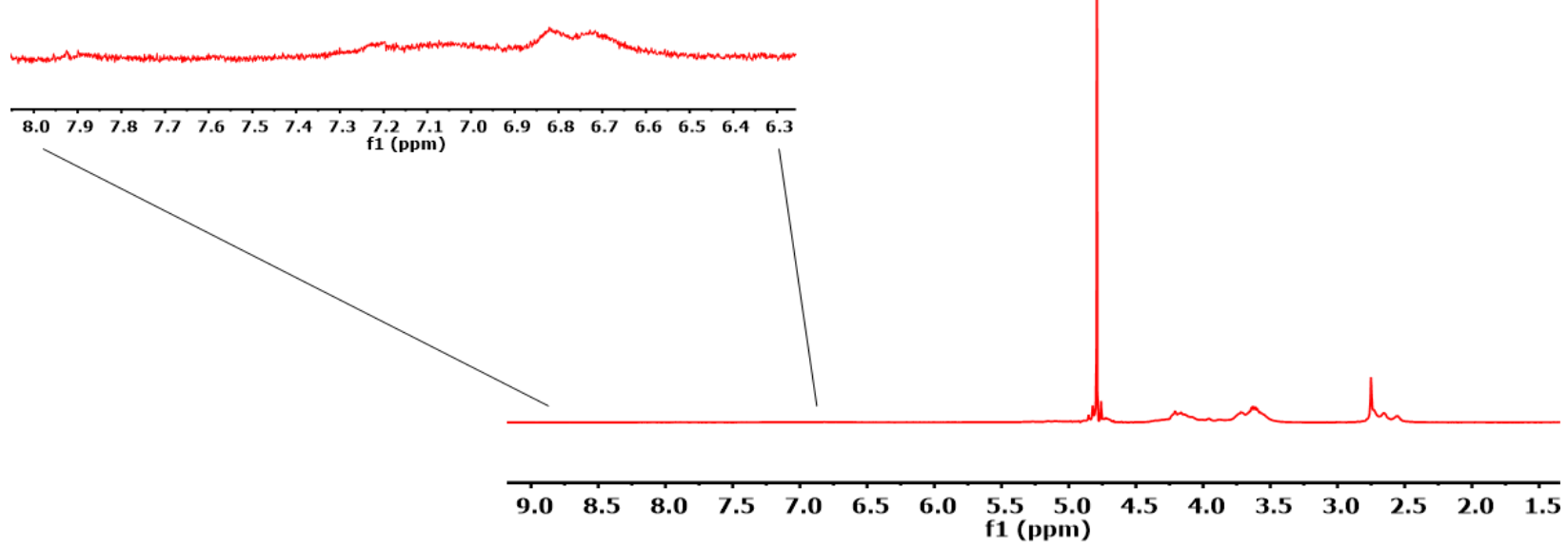

Figure S6. ${ }^{1} \mathrm{H}$ NMR spectrum FITC-labeled EPSG in $\mathrm{D}_{2} \mathrm{O}$. 


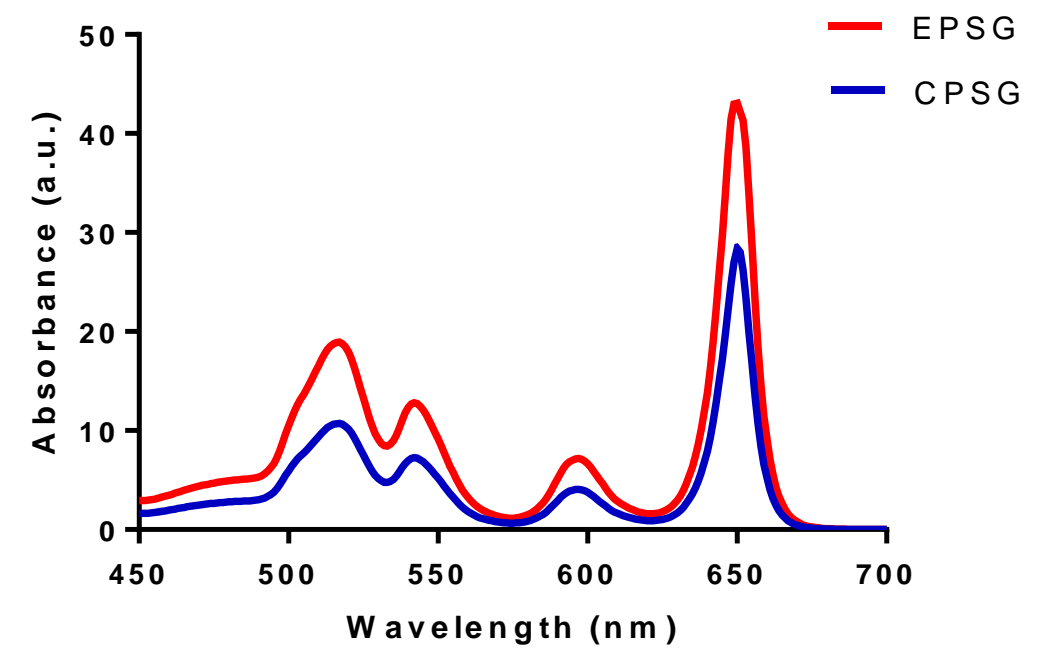

Figure S7. UV-Vis data of porphyrin loaded EPSG and CPSG. 